OPEN ACCESS

Edited by:

Lin Xu,

Institute of Plant Physiology and Ecology, Shanghai Institutes for Biological Sciences, China

Reviewed by:

Li Yang,

University of North Carolina Chapel Hill, USA

Pingli Lu,

Fudan University, China

*Correspondence: Andriy Bilichak, Lethbridge Research Centre, Agriculture and Agri-Food Canada, Lethbridge, AB T1J 4P4, Canada andrii.bilichak@agr.gc.ca

Specialty section: This article was submitted to Plant Cell Biology, a section of the journal Frontiers in Plant Science

Received: 05 July 2015 Accepted: 13 August 2015

Published: 28 August 2015

Citation:

Bilichak A, Luu J and Eudes F (2015) Intracellular delivery of fluorescent protein into viable wheat microspores using cationic peptides.

Front. Plant Sci. 6:666 doi: 10.3389/fpls.2015.00666

\section{Intracellular delivery of fluorescent protein into viable wheat microspores using cationic peptides}

\author{
Andriy Bilichak*, Justin Luu and François Eudes \\ Lethbridge Research Centre, Agriculture and Agri-Food Canada, Lethbridge, AB, Canada
}

Microspores are specialized generative cells with haploid genome that demonstrate the amenability toward embryogenesis under certain conditions. The induced microspore culture technique is largely exploited by the breeding programs of wheat and other crops due to its high efficiency for generation of the large number of haploid plants in the relatively short period of time. The ability to produce mature double haploid plant from a single cell has also attracted attention of the plant biotechnologists in the past few years. More importantly, the possibility to deliver proteins for improvement of embryogenesis and the genome modification purposes holds great potential for transgene-free wheat biotechnology. In the present study, we examined the ability of cationic and amphipathic cell penetrating peptides (CPPs) to convey a covalently-linked mCherry protein inside the viable microspores. We demonstrate that the affinity of CPPs to the microspore cells dependents on their charge with the highest efficiency of CPP-mCherry binding to the cells achieved by cationic CPPs (penetratin and R9). Additionally, due to overall negative charge of the microspore cell wall, the successful uptake of the protein cargo by live microspore cells is attained by utilization of a reversible disulfide bond between the R9 CPP and mCherry protein. Overall, the approach proposed herein can be applied by the other biotechnology groups for the fast and efficient screening of the different CPP candidates for their ability to deliver proteins inside the viable plant cells.

Keywords: microspores, cell-penetrating peptides, R9, direct protein delivery, wheat

\section{Introduction}

Bread wheat (Triticum aestivum L.) is one of the major economically important crops worldwide that provides around one fifth of the calories to human population (Wang et al., 2014a). The creation of necessary genetic diversity, introduction of the new traits and the generation of improved cultivars for wheat involves predominantly classical breading. The last, in turn, relies on the techniques which can generate a large number of haploid plants either by pollination of wheat with alien species (Hordeum bulbosum, maize or sorghum) (Barclay, 1975; Laurie and Bennett, 1988a,b) or by microspore and anther culture. Despite some benefits of the wheat pollination technique, the microspore culture produces the large number of haploid plants in the shorter period of time (Touraev et al., 1996; Hul and Kasha, 1997; Hu and Kasha, 1999). More importantly, being a synchronized population of single cells with haploid genome and morphogenic potential, the microspore technique offers enormous prospective for improvement of embryogenesis in the culture as well as the possibility of genome editing at a single-cell level. Substantial effort has been made to develop methods for transformation of microspores and microspore-derived tissue. 
Overall, depending on the physiological stage that transformation occurs at, the procedures can be classified as: gametophytic and sporophytic (Resch and Touraev, 2010). Whereas the former one encompasses pollination using either the transformed mature pollen or in vitro cultured pollen grains derived from transformed microspores, the latter one utilizes haploid microspore-derived embryos as the plant material for stable transformation. In most of the cases the transformation is performed using either A. tumefaciens or electroporation or bombardment (Brisibe et al., 2000; Folling and Olesen, 2001; Kumlehn et al., 2006; Chauhan and Khurana, 2011; Brew-Appiah et al., 2013). While being efficient for the introduction of foreign DNA in the wheat genome, unfortunately, neither of these techniques currently offers the possibility of protein delivery into viable microspore cells. Direct introduction of the protein molecules into microspores at the certain physiological stage can potentially be utilized for improvement of the culture embryogenesis and generation of the higher number of green haploid plants for the breeding programs. The broader application includes the exploitation of the designed endonucleases (i.e., Zinc Finger Nucleases, Transcription activator-like effector nucleases, CRISPR/Cas9, and meganucleases) in the form of proteins for the permanent introduction of mutations at the selected loci. Moreover, delivery of the functional enzymes in the form of proteins eliminates the possibility of generating the plants containing transgenes and the resulting product is expected to be void of regulation covering GMO crops (Voytas and Gao, 2014).

An alternative technique for the cargo delivery into live cells has been proposed in the recent years that utilizes the natural ability of cell penetrating peptides (CPPs) to internalize protein, DNA or nanoparticles into animal and plant cells (Chang et al., 2005, 2014; Liu et al., 2013). The first CPP, discovered in 1988, was the domain of transcriptional activator protein (Tat) of the human immunodeficiency virus type 1 (HIV-1) (Frankel and Pabo, 1988; Green and Loewenstein, 1988). Later on, it has been established that the presence of the basic amino acids in the CPP sequence is prerequisite for its translocation through the plasma membrane and accumulation in the cytoplasm and nucleus (Vivès et al., 1997). Subsequently, a number of naturally-occurring and synthetic CPPs were identified with the different properties capable of delivering a wide range of bioactive molecules into the living cells (Fonseca et al., 2009; Huang et al., 2013; Chang et al., 2014; Wang et al., 2014b). Depending on the origin they can be classified as protein-derived, synthetic and chimeric (Lindgren and Langel, 2011). Additionally, based on their physical-chemical properties CPPs can be divided into amphipathic, hydrophobic, and cationic peptides.

The interaction between CPP and the cargos can be either covalent or non-covalent. Whereas, the former one is usually made through disulphide bridges, ester or peptide bonds, the latter one relies on the weak van der Waals forces, electrostatic interactions, and hydrophobic effects (Chang et al., 2014). Previously, we have shown that cationic peptides (Tat and Tat2) are able to deliver protein and DNA molecules in the form of non-covalent complexes into triticale microspores (Chugh et al., 2009). Nevertheless, it still remains vague whether the covalently-linked CPPs can convey the protein molecules in their native state inside the live microspores and how CPPs with different physical-chemical properties interact with the microspore cells. In the present study, we selected two cationic [penetratin (Derossi et al., 1994) and R9 (Futaki, 2002)] and two amphipathic [transportan (Pooga et al., 1998) and model amphipathic peptide (Oehlke et al., 1998)] CPPs and examined their ability to deliver functional covalently-linked mCherry protein into live microspore cells. For this, in-frame fusion of proteins with CPP residues at the $\mathrm{N}$-terminus were purified from bacterial culture and the screening for the best peptide for mCherry conveyance inside the microspore cells was conducted. The data presented in this communication reveals the drastic difference between CPPs for their ability to interact with microspores as well as the importance of utilization of the temporary covalent bonds for the protein cargo internalization inside viable cells.

\section{Materials and Methods}

\section{Plant Cultivation}

Wheat seeds (cultivar AC Andrew) were germinated and grown in the Cornell mix as described in Asif et al. (2013) and Sinha and Eudes (2015). The plants were treated with $2.5 \mathrm{ml} / \mathrm{l}$ of Tilt $^{\mathrm{TM}}$ (propiconazole, Syngenta) before the tillering stage No. 2 as per (Zadoks et al., 1974) and Intercept ${ }^{\mathrm{TM}}(0.004 \mathrm{~g} / \mathrm{l}$ of soil, Imidacloprid, Bayer) once sufficient root development was established to control pests. The tillers were harvested when the microspores reached mid-to-late uninucleate stage. The tillers were kept at $4{ }^{\circ} \mathrm{C}$ for 3 weeks with their bases in distiled water and their heads wrapped in aluminum foil. Following 3 weeks \pm 3 days of pre-treatment, the spikes were extracted from their tillers and after evaluation of their general appearance, only the most homogenous spikes were used for microspores isolation.

\section{Microspores Isolation}

Isolation of microspores was done as described previously (Asif et al., 2013; Sinha and Eudes, 2015). Briefly, the stage of microspores was verified using a median floret and an acetocarmine staining. Twelve spikes per extraction were surface sterilized with $10 \%(\mathrm{v} / \mathrm{v})$ bleach (5.25\% sodium hypochlorite) for $3 \mathrm{~min}$ followed by three washes with sterile double distiled water with constant agitation. Florets were aseptically dissected and transferred to a sterile and refrigerated $110 \mathrm{ml}$ Warring blender cup (VWR International) containing $50 \mathrm{ml}$ of filter sterilized extraction solution at $4^{\circ} \mathrm{C}\left(14 \mathrm{mM} \mathrm{KNO}_{3}, 1.76 \mathrm{mM}\left(\mathrm{NH}_{4}\right)_{2} \mathrm{SO}_{4}\right.$, $1.47 \mathrm{mM} \mathrm{KH} \mathrm{PO}_{4}, 0.56 \mathrm{mM} \mathrm{CaCl}_{2}, 0.38 \mathrm{mM} \mathrm{MgSO}, 0.1 \mathrm{mM}$ $\mathrm{FeSO}_{4}, 0.1 \mathrm{mM} \mathrm{Na} 2$ EDTA, $0.9 \mathrm{mM}$ MES and $400 \mathrm{mM}$ mannitol, $\mathrm{pH}$ 6.5). The florets were blended twice for $7 \mathrm{~s}$ at low speed $(18,000 \mathrm{rpm})$. The extract was filtered through $100 \mu \mathrm{m}$ sterile mesh (VWR International) and the cells were then pelleted by centrifugation ( $100 \mathrm{~g}$ for $5 \mathrm{~min}$ at $4^{\circ} \mathrm{C}$ ) using a swinging bucket rotor (Eppendorf AG, Hamburg, Germany). After removing the supernatant, the pellet was resuspended in $16 \mathrm{ml}$ of icecold extraction solution. Following a second spin (100 $\mathrm{g}$ for $5 \mathrm{~min}$ at $4^{\circ} \mathrm{C}$ ), the microspore cells were resuspended in $6 \mathrm{ml}$ of pre-chilled, sterile $20 \%$ maltose solution and $1 \mathrm{ml}$ of extraction medium was layered on top. The content was centrifuged at $100 \mathrm{~g}$ 
for $13 \mathrm{~min}$ at $4^{\circ} \mathrm{C}$ and the viable microspore cells in the interphase were transferred to the fresh $15 \mathrm{ml}$ tube. The microspores were washed again with $15 \mathrm{ml}$ of extraction solution and resuspended to the final concentration of 500 cells per microliter.

\section{Plasmid Constructions}

Protein expression plasmids pET45b(+)::Cys-mCherry and pET45(+)::CPP-Cys-mCherry were generated by $5^{\prime}$ in-frame fusion of sequences coding either for cysteine (Cys) or CPPs (either R9, penetratin, transportan or model amphipathic peptide) followed by Cys to mCherry coding sequence using PCR (mCherry GenBank ID: JN717246.1). Since mCherry protein does not contain cysteinyl residues, the codon for cysteine was introduced into CDS in order to facilitate reversible covalent linkage formation with thiol-reactive nitropyridyl (Npys) $\mathrm{Arg}_{9}$ peptide (Cys (Npys)-(D-Arg) $)_{9}$ ). A 3'-primer contained a sequence coding for six histidines to aid in the downstream protein purification (Supplementary Table 1). The Cys-mCherry and CPP-Cys-mCherry PCR products were cloned as NcoI and HindIII fragments into linearized pET45b $(+)$ plasmid. The recombinant constructs were verified by sequencing.

\section{Protein Overexpression and Purification from Bacterial Culture}

The constructed plasmids were transformed into E.coli strain BL21 (DE3) (Novagen, USA). Single colony of every construct was inoculated into $25 \mathrm{ml}$ of $\mathrm{LB}$ (the starter culture) and was grown overnight at $37^{\circ} \mathrm{C}$ with shaking at $250 \mathrm{rpm}$ in the presence of $100 \mu \mathrm{g} / \mathrm{ml}$ of carbenicillin. The following day, the starter culture was transferred to $500 \mathrm{ml}$ of LB supplemented with carbenicillin and was grown at $37^{\circ} \mathrm{C}$ until $\mathrm{OD}_{600}$ reached 0.5 . The culture was moved to $16^{\circ} \mathrm{C}$ and the protein expression was induced with $1 \mathrm{mM}$ IPTG. Following $18 \mathrm{~h}$ of protein induction, the bacterial culture was harvested by centrifugation and the pellet was re-suspended in $25 \mathrm{ml}$ of a His-Tag buffer A $(20 \mathrm{mM}$ HEPES, $0.3 \mathrm{M} \mathrm{NaCl}, 5 \%$ glycerol and $40 \mathrm{mM}$ imidazole, $\mathrm{pH}$ 7.5) supplemented with EDTA-free protease inhibitor cocktail (Roche). Cells were disrupted by sonication (50\% intensity, $30 \mathrm{~s}$ on, 1 min off time, four cycles, model Q55, Qsonica), and the insoluble debris were removed by centrifugation $(18,500 \mathrm{~g}, 1 \mathrm{~h}$ at $4^{\circ} \mathrm{C}$ ). The clarified supernatant was applied directly onto $1 \mathrm{ml}$ His-Trap column (GE Healthcare Life Sciences) equilibrated with the His-Tag buffer A using an FPLC system (AKTA purifier, GE Healthcare Life Sciences). The elution of bound protein was done using a linear gradient of His-Tag buffer B (20 mM HEPES, $0.3 \mathrm{M} \mathrm{NaCl}, 5 \%$ glycerol and $500 \mathrm{mM}$ imidazole, $\mathrm{pH}$ 7.5) from 0 to $100 \%$. Fractions containing the target protein (assessed by the mCherry absorbance at $587 \mathrm{~nm}$ ) were combined together and concentrated till $0.5 \mathrm{ml}$ using $10 \mathrm{~K}$ Amicon Ultra-15 spin concentrators (EMD Millipore). The protein was filtered through $0.2 \mu \mathrm{m}$ low-protein binding filter (EMD Millipore) and loaded onto HiLoad 16/60, Superdex 200 prep grade size exclusion column (SEC, GE Healthcare Life Sciences) primed with SEC buffer (20 mM HEPES, 0.15 M NaCl, pH 7.5) using FPLC system. Following gel filtration step the fractions containing CPPmCherry protein were analyzed on $10 \%$ SDS-PAGE gel. The fractions with more than $90 \%$ purity were combined together

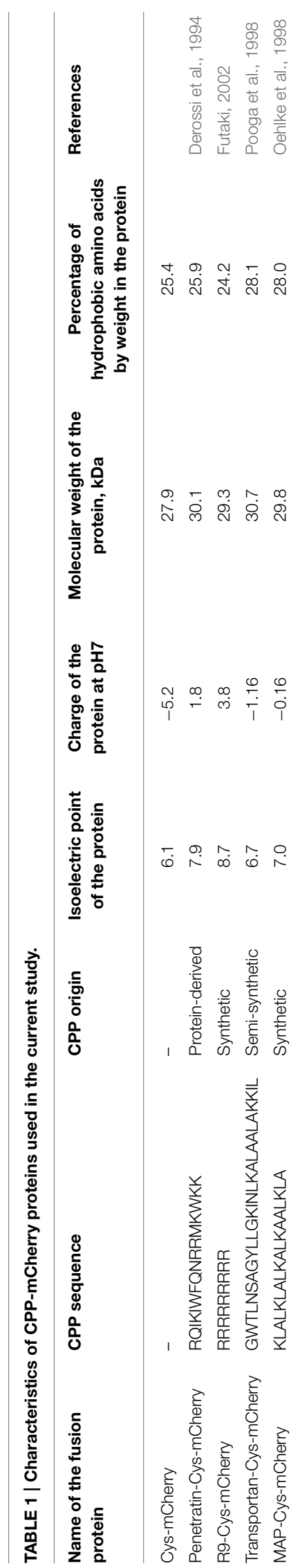


and concentrated using spin concentrators till at least $50 \mu \mathrm{M}$. Glycerol was added to the fractions till the final concentration of $5 \%$ and the proteins were stored at $-80^{\circ} \mathrm{C}$.

\section{R9-mCherry Complex Formation}

To prepare R9-mCherry complex with the covalent bond through disulfide bridge, purified Cys-mCherry protein $(50 \mu \mathrm{l} ; 1 \mathrm{nmol}$ in HEPES SEC buffer, $\mathrm{pH} 7.5$ ) and up to $30 \mathrm{nmol}$ of Cys-(Npys)(D-Arg) ${ }_{9}$ peptide in $50 \mu \mathrm{l}$ of water (AnaSpec) were combined and allowed to react at room temperature for at least $1 \mathrm{~h}$ with no mixing (Liu et al., 2014). The non-covalent complex formation was done by mixing Cys-mCherry protein $(50 \mu \mathrm{l} ; 1 \mathrm{nmol}$ in HEPES SEC buffer, $\mathrm{pH} 7.5$ ) and $1 \mathrm{nmol}$ of L-Arg 9 peptide in $50 \mu \mathrm{l}$ of water (AnaSpec). The solution was incubated for $1 \mathrm{~h}$ with no mixing at room temperature.

\section{Microspores Treatments}

Microspores were treated either with in-frame fusion or in vitro combined $\mathrm{Arg}_{9}$-mCherry protein. Protein solutions (up to $2 \mathrm{nmol}$ in $100 \mu \mathrm{l}$ ) were mixed with $100 \mu \mathrm{l}$ of microspores (50,000 cells) in extraction buffer and incubated for $1 \mathrm{~h}$ (unless otherwise indicated) at room temperature. Following incubation, microspores were washed three times with $2 \mathrm{ml}$ each of extraction buffer to remove the excess of protein. Microspores were resuspended in $200 \mu \mathrm{l}$ of extraction buffer and fluorescein diacetate (FDA) was added till $2.4 \mu \mathrm{M}$ in order to visualize viable cells (Sinha and Eudes, 2015). All experiments were done in three biological replicates.

\section{Collecting the Data using Plate Reader and Microscopy Imaging}

Microspores viability and the level of intensity after treatment with CPP-Cys-mCherry proteins were measured using BioTek Synergy Mx microplate reader (BioTek Instruments, Inc., USA). For this, the microspore solution was resuspended and 12,500 cells in $50 \mu \mathrm{l}$ volume were pipetted into every well of the black 96-well plate (Costar, Fisher Scientific). For FDA and mCherry measurements, the fluorescent reading was done at excitation/emission wavelengths of $492 / 517$ and 587/610 nm, respectively. The data normalization was done by setting the fluorescent reading from the FDA measurement in the untreated control sample to $100 \%$. For the mCherry signal detection, the reading from untreated control was set to 1 and the fold difference as compared to control was calculated. No crossreading was detected between two fluorescent signals under aforementioned conditions. All measurements were done in three biological and two technical repeats.

The visual examination of treated microspores was done using both EVOS FL cell imaging system (Life Technologies) and confocal laser scanning microscope Olympus, FV1000 (Olympus).

\section{Statistical Analysis}

The statistical significance was confirmed by single-tailed paired Student's $t$-test with $\alpha=0.05$ and the single factor ANOVA.
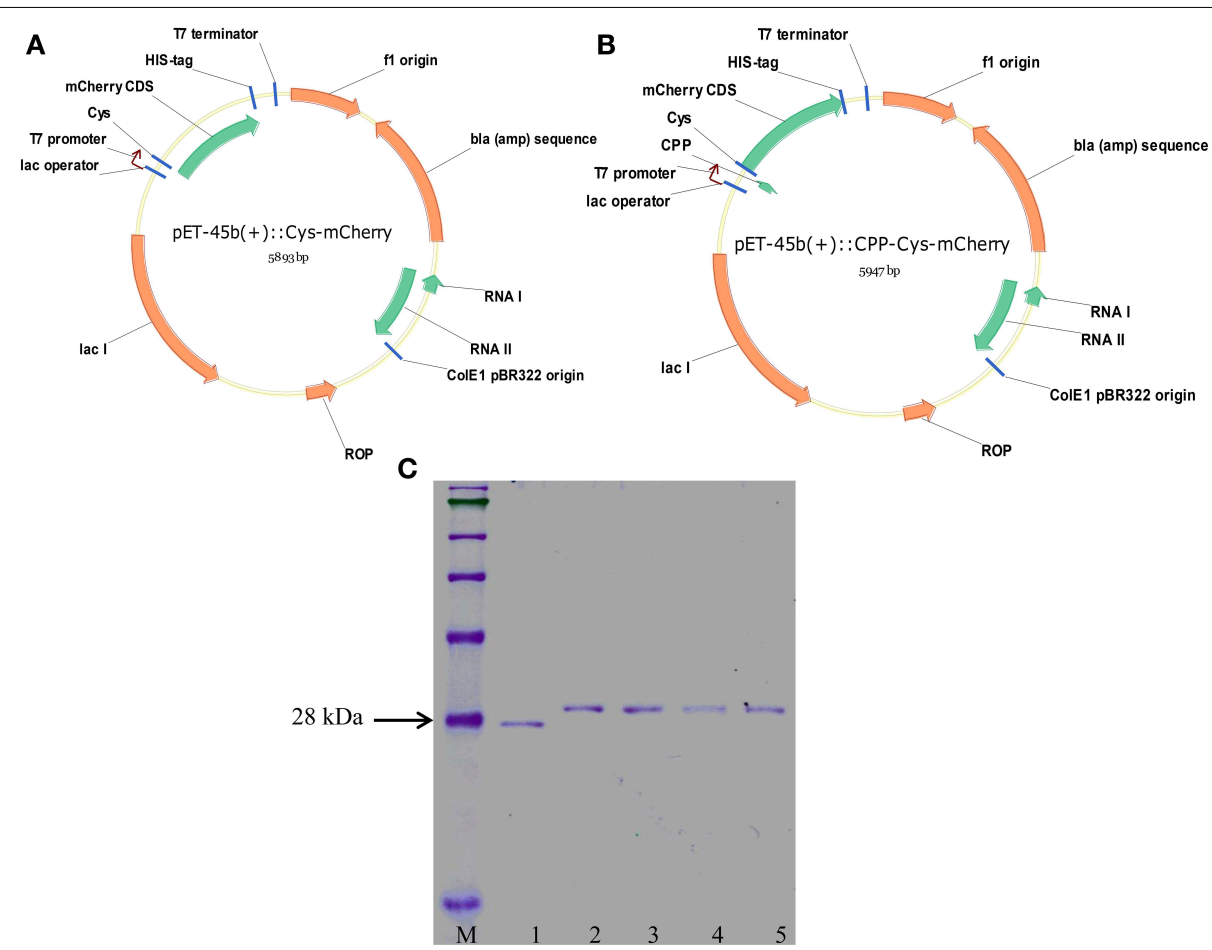

FIGURE 1 | Schematic map of generated vectors used for purification of Cys-mCherry (A) and CPP-Cys-mCherry (B) proteins from bacterial culture. (C) SDS-PAGE analysis of the purified proteins:
1. Cys-mCherry; 2, penetratin-Cys-mCherry; 3, R9-Cys-mCherry; 4, transportan-Cys-mCherry; 5, MAP-Cys-mCherry; M, molecular weight protein marker. 


\section{Results}

\section{Selection of CPPs for In-frame Fusion with mCherry Protein}

The mCherry protein was chosen as a cargo due to its stability, fast maturation time, high level of fluorescence, and low auto fluorescence level of microspores in the mCherry spectrum range. Four distinct CPPs were picked up for microspore transfection experiments based on their physicalchemical properties (Table 1). The nucleotide sequences coding for corresponding CPPs and $6 \mathrm{xHis}$ sequence were fused inframe to the coding sequence of mCherry at the $5^{\prime}$ - and $3^{\prime}$ ends, respectively, using PCR. The resulting PCR fragments were cloned into pET45b $(+)$ plasmid (Figures 1A,B). The proteins were purified from bacterial culture with the final purity of more than $98 \%$ (Figure 1C). All mCherry fusions demonstrated same intensity of fluorescence in regard to their concentration indicating that CPPs did not affect the protein confirmation (Supplementary Figure 1). The mCherry protein bearing the cysteine at the N-terminus was used as a no-CPP control treatment for all microspore transfection experiments.

\section{The Interaction of CPP-mCherry Proteins with Microspore Cells}

Two cationic (R9 and penetratin) and two amphipathic (transportan and MAP) peptides were used to test their ability to translocate covalently linked mCherry protein into viable microspore cells. Treatment of microspores with equal amounts
( $1 \mathrm{nmol}$ each) of either Cys-mCherry or CPP-Cys-mCherry proteins for $1 \mathrm{~h}$, followed by examination using fluorescent microscopy, revealed that both cationic CPPs demonstrate the highest binding to the negatively charged microspore's exine as compared to amphipathic ones (Figure 2A). The amphipathic CPP-Cys-mCherry proteins showed interaction with the microspore cell wall that was the lowest among CPPmCherry fusions tested. Treatment of the cells with the R9-CysmCherry protein displayed the highest intensity of fluorescent signal among tested CPP-fusion proteins (Figure 2B, Student's $t$-test, $P<0.05$ ), hence the R9-fusion protein was selected as the candidate for the further detailed examination of its CPP properties. No decrease in microspore viability was observed for any of the treatments under tested conditions (Figure 2C, Student's $t$-test, $P>0.05$ ).

\section{Evaluation of the R9-Cys-mCherry Interaction with the Wheat Microspores}

Further analysis of the R9-Cys-mCherry binding to the microspore cells demonstrated that the effect was dosedependent (Figure 3A) and the intensity of fluorescent signal demonstrated linear correlation with the amount of applied protein in a range from 0.25 to $2 \mathrm{nmol}$ (Figure $3 \mathrm{~B}, R^{2}=0.86$ ). The viability of the treated microspores was not compromised under the treatment conditions (Figure 3C). The interaction of R9-Cys-mCherry with the cells apparently occurred mostly on the surface of the cells, since as little as $5 \mathrm{~min}$ was required for the fluorescent signal to achieve its maximum intensity when

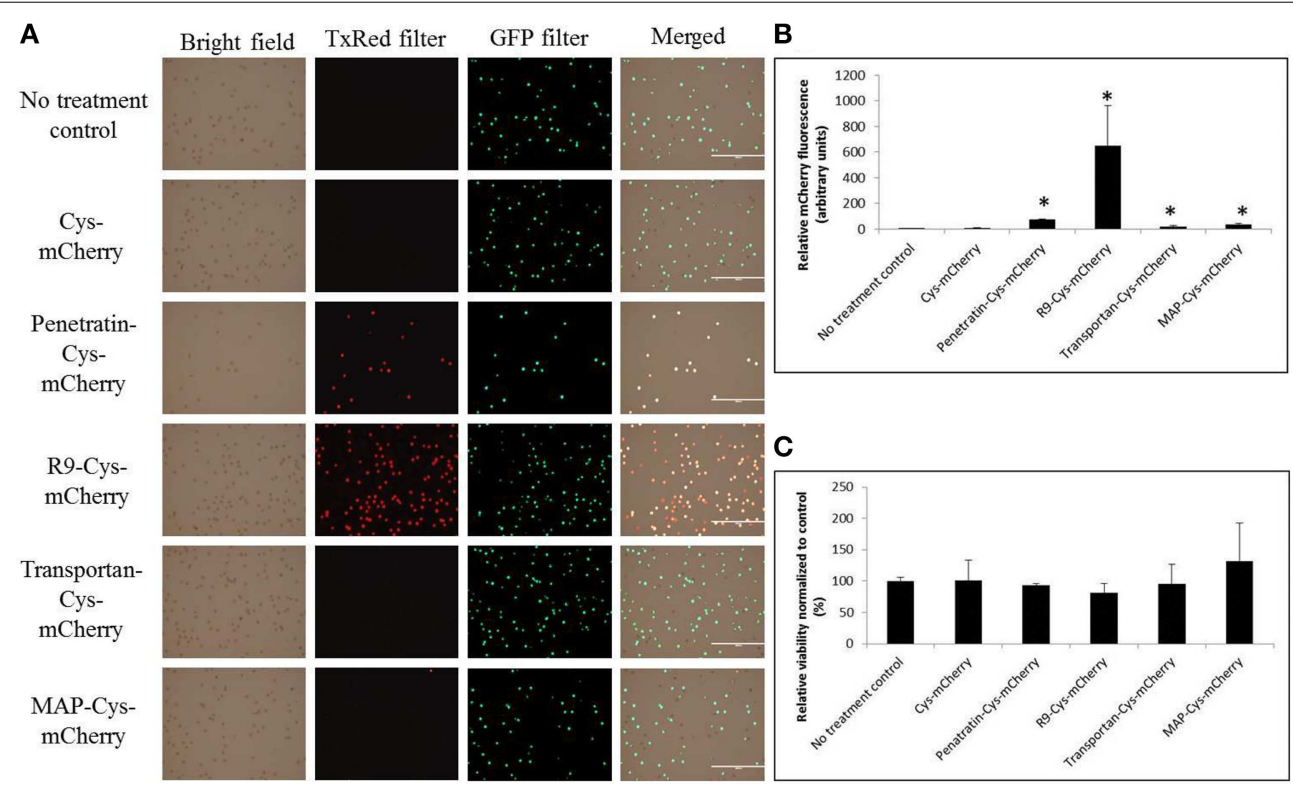

FIGURE 2 | The effect of different CPPs on the binding capacity of the CPP-Cys-mCherry proteins to the microspore cells. (A) Microscopy imaging of the treated microspores. Microspores were subjected to incubation with $1 \mathrm{nmol}$ of one of the proteins for $1 \mathrm{~h}$, followed by three washing steps and examination using EVOS FL cell imaging system (Life Technologies). The TxRed and GFP LED light cubes were used to visualize fluorescent signals from mCherry and FDA stain, respectively. The horizontal bars on the merged images indicate $1 \mathrm{~mm}$ scale. (B,C) Quantification of intensity of fluorescent signals for mCherry and FDA chromophores, respectively, using BioTek Synergy Mx microplate reader. Data are shown as average calculated from three independent repeats with SD. For the data normalization see the Materials and Methods Section. The stars indicate statistically significant difference as compared to Cys-mCherry treatment (Student's $t$-test, $\alpha=0.05$ ). 


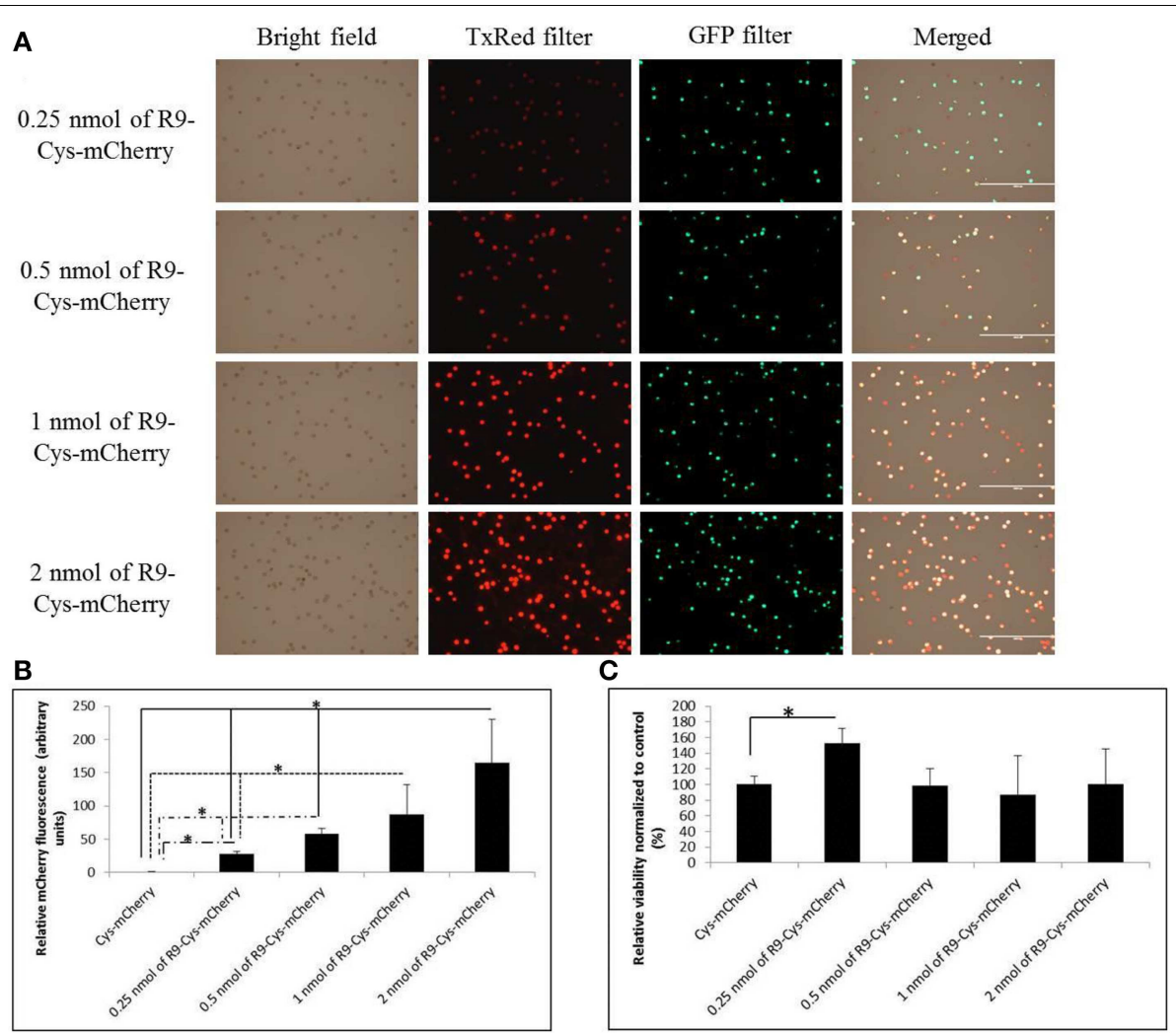

FIGURE 3 | Evaluation of the binding capacity of the R9-Cys-mCherry protein to the microspore cells. (A) Microscopy imaging of the microspores treated with different amounts of the R9-Cys-mCherry protein. (B,C) Quantification of the fluorescence intensity from the mCherry and FDA chromophores, respectively, using BioTek Synergy Mx microplate reader.
Data are shown as average calculated from three independent repeats with $\mathrm{SD}$. For the data normalization see the Materials and Methods Section. The stars indicate statistically significant difference between connected bars (Student's $t$-test, single factor ANOVA, $\alpha=0.05 ; R^{2}=0.86$ for treatments displayed in $\mathbf{B})$.
$1 \mathrm{nmol}$ of the protein was used (Figure 4A, Student's $t$-test, $P>$ 0.1 ). Furthermore, the binding of the protein to the microspore outer surface was temperature-dependent (Figure 4B), although the microspore viability was significantly compromised when the treatment was performed at $37^{\circ} \mathrm{C}$ for $1 \mathrm{~h}$ (Figure 4D).

\section{Temporary Covalent Bond between R9 and mCherry is Required for Protein Cargo Delivery into Viable Wheat Microspores}

Detailed examination of the microspores treated with R9-CysmCherry using confocal laser scanning microscopy revealed that the majority of the protein was trapped on the exine of microspores (Figure 5). We hypothesized that the negative charge of exine (Salter et al., 2002) caused a strong binding of the R9-Cys-mCherry protein to the surface of the cells and supplementing of R9 peptide that can form a reversible covalent bond with the target protein is required for the protein to be internalized inside the cells. Having an additional cysteinyl residue at the $\mathrm{N}$-terminus of the protein allowed us to attach an R9 peptide [Cys (Npys)-(D-Arg) $)_{9}$ through asymmetrical disulfide bond that can be dissociated under reducing conditions inside a cell (Liu et al., 2014). The unreacted CPPs may, apparently, coat Cys-mCherry molecules through electrostatic interaction and, thus, further aid in the translocation of the protein through exine and plasma membrane by making the mCherry protein overall positively charged. Due to the known cytotoxicity of CPPs (Scheller et al., 1999), we first examined the effect of Cys (Npys)-(D-Arg) 9 peptide on the microspore viability. The conjugation reaction was performed for at least $1 \mathrm{~h}$ at room temperature as described previously (Liu et al., 2014). The microspore cells demonstrated elevated sensitivity to the tested peptide at the Cys-mCherry to CPP molar ratios higher than 1:1 (Figure 6). Hence, the molar ratio of 1:1 was used for the transfection of microspores [ $1 \mathrm{nmol}$ of Cys-mCherry

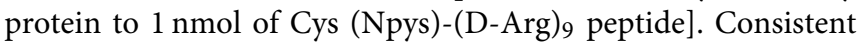
with our hypothesis, supplementing of D-R9 peptide which was able to form disulfide bridges with the mCherry protein resulted in detection of viable microspores with internalized Cys-mCherry protein as revealed by confocal laser scanning fluorescent microscopy (Figure 5). The Cys-mCherry protein was predominantly localized to the cytoplasm and nucleus of the cells and was excluded from the vacuoles. In contrast, we were not able to detect transfected microspores when noncovalent complex formation was performed using L-R 9 peptide ( $1 \mathrm{nmol}$ of Cys-mCherry protein to $1 \mathrm{nmol}$ of $\mathrm{L}-\mathrm{Arg}_{9}$ peptide). No fluorescent signal was detected when microspores were 


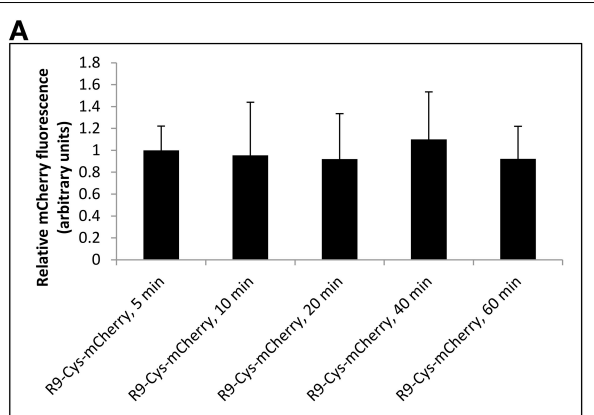

C

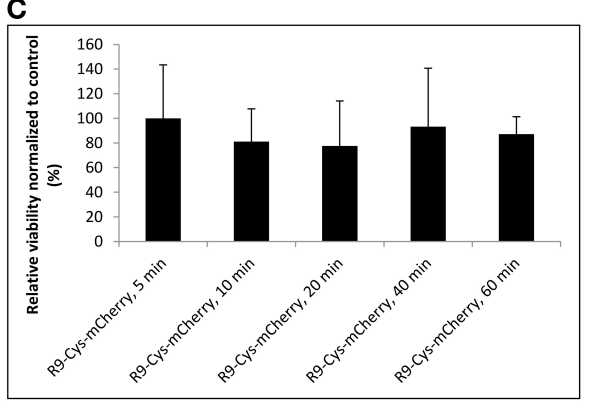

FIGURE 4 | The effect of different time and temperature treatments on the binding capacity of the R9-Cys-mCherry protein to the microspore cells (A,B, respectively) and on the microspore viability (C,D). For all experiments the treatment was done with $1 \mathrm{nmol}$ of the R9-Cys-mCherry protein, followed by microspore washing for three times

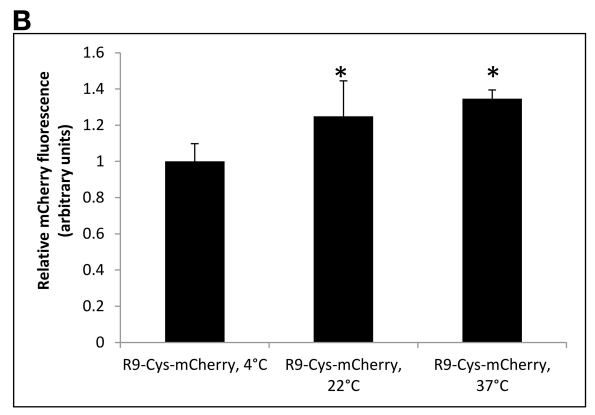

D

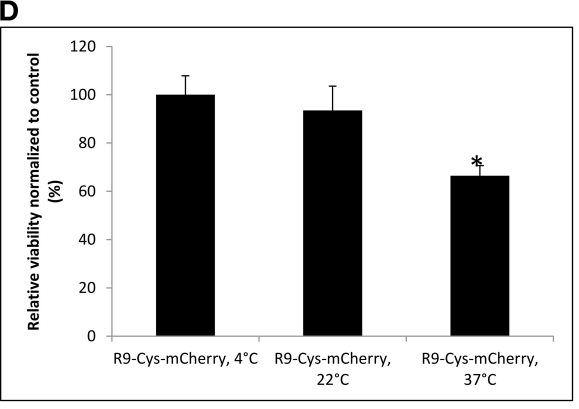

and quantification using BioTek Synergy Mx microplate reader. Data are shown as average calculated from three independent repeats with SD. For the data normalization see the Materials and Methods Section. The stars indicate statistically significant difference as compared to untreated control (Student's $t$-test, $\alpha=0.05$ ). treated with Cys (Npys)-(D-Arg) 9 peptide alone (data not shown).

\section{Discussion}

The ability to deliver proteins into embryogenic cells/tissues holds a great potential both for academic and applied studies. Due to the relatively short half-life of proteins, the necessary effects can be achieved transiently and at a particular stage of the cell development. The possible implications include temporary changing the fate of the tissue development, enhancing the embryogenesis level, and even permanent modification of the plant genome. The last approach has been successfully established in animal cells through delivery of designed endonucleases in the form of proteins using CPPs for the transgene-free genome editing purpose (Liu et al., 2014; Ramakrishna et al., 2014). In both cases, synthetic R9 peptide has been used for the protein translocation. The net positive charge of the cargo molecule seems to be the requirement for successful cellular uptake in the animal cells. For instance, the relatively large protein molecules like Zinc Finger Nucleases (around $45 \mathrm{kDa}$ ) that belong to the family of positive supercharged proteins are able to cross the plasma membrane of the animal cells in active form (Gaj et al., 2012; Liu et al., 2015). At the same time, a number of amphipathic CPPs have been ascribed for the animal cells which are characterized by the helical structure and the presence of lysine residues.

In this study, we made an attempt to compare two different classes of CPPs for their ability to interact with the microspore cells and to internalize protein cargo. Consistent with the previous reports, we observed that cationic peptides demonstrate high affinity for the plant cells (Figures 1A,B) (Chang et al., 2005). For instance, previously, it has been reported that either covalent (Chang et al., 2005) or non-covalent (Chang et al., 2007) complexes with either Tat or R9 were able to convey fluorescent proteins inside the onion and tomato roots and epidermal cells. Additionally, in line with our data neither of the treatments had a cytotoxic effect on the wheat microspores when CPPs where permanently fused to the protein (Figure 1C) (Chang et al., 2005). On the other hand, to our surprise, neither of the amphipathic CPPs demonstrated strong interaction with microspore cells. These data come in the disagreement with the previous report where both cationic (penetratin, Tat $48-60$ ) and amphipathic (transportan and MAP) CPPs were tested for their ability to internalize covalently linked, through disulfide bond, pentapeptide cargo (labeled with the 2-amino benzoic acid fluorophore) into animal cells (Hallbrink et al., 2001). Both amphipathic CPPs demonstrated the highest level of uptake by Bowes human melanoma cells. It has been hypothesized that the difference in the efficiency of cargo delivery between the amphipathic and cationic CPPs is due to the ability of the former ones to enter and exit cells more easily since they are in equilibrium over the plasma membrane while the members of the latter class are not (Hallbrink et al., 2001). At the same time, the kinetics of CPP trafficking through the membrane is probably dependent not only on peptides, but also on the membrane area and lipid bilayer composition, and consequently is cell-type specific. 


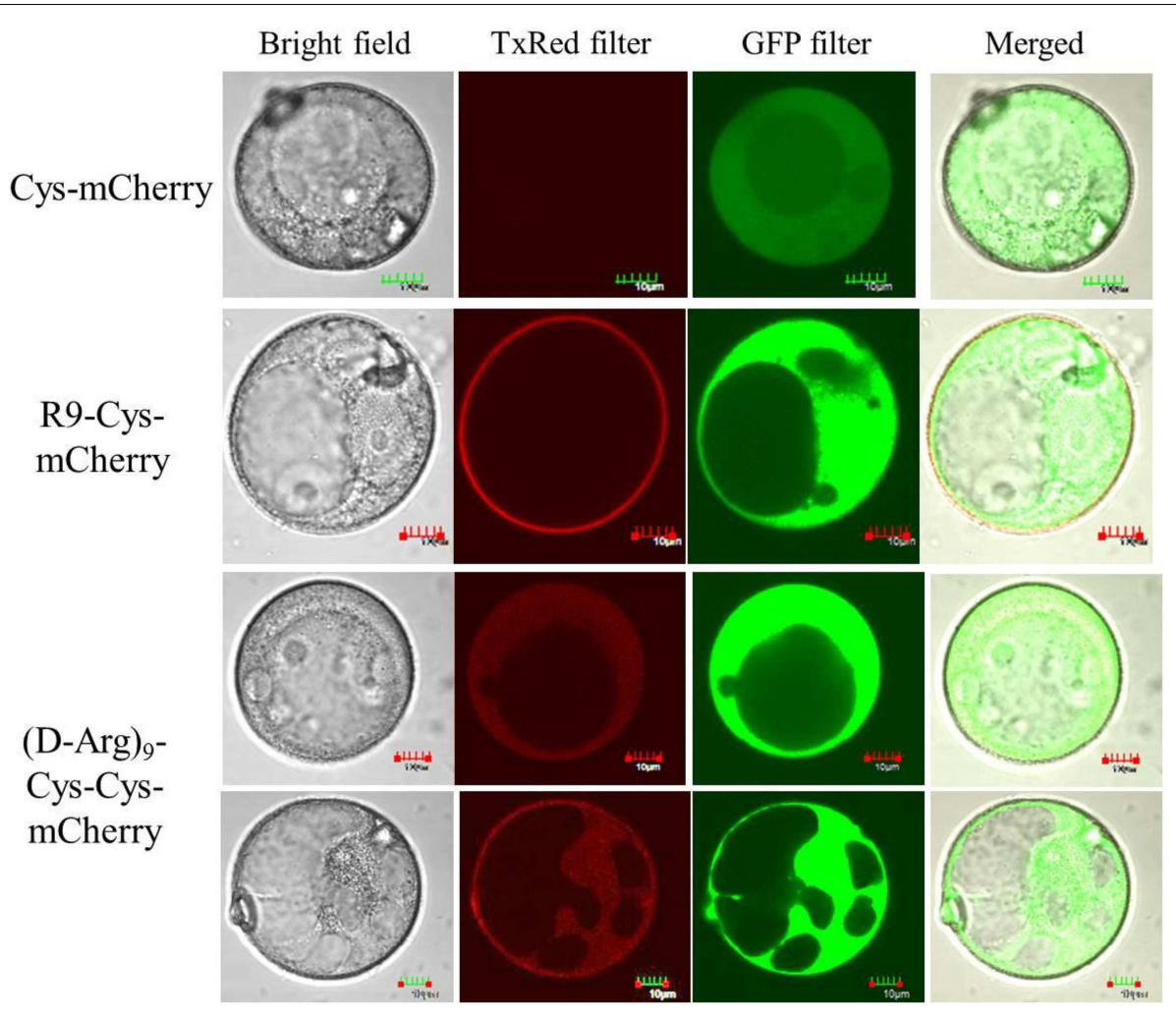

FIGURE 5 | Analysis of mCherry localization in the microspore cells using confocal laser scanning microscopy. Microspores were incubated with either Cys-mCherry, R9-Cys-mCherry or (D-Arg)g-Cys-Cys-mCherry complex at 1:1 molar ratio overnight at room temperature. Following incubation, the cells were washed and stained with $2.4 \mu \mathrm{M}$ FDA to visualize viable microspores. The TxRed and GFP filter sets were used to capture the fluorescent signals from mCherry and FDA, respectively.
The microspore cell is composed of three parts: exine, intine, and protoplast (Tang et al., 2013). The exine of microspores consists of the sporopollenin that is assumed to have phenolics and polyhydroxylated unbranched aliphatics, coupled by ester and ether linkages, which provide this biopolymer with its characteristic resistance to chemical degradation and tolerance to ambient stress conditions (Quilichini et al., 2010). Intine, in turn, is composed of cellulose and pectin. The only access to plasma membrane for the CPP-cargo complex is assumed to be through the single micropore or germ pore (Chugh et al., 2009). The strong binding of cationic CPP-protein fusions like R9Cys-mCherry and penetratin-Cys-mCherry to the microspore cells is apparently due to high density of negative charges in the sporopollenin matrix that makes it amphiphilic with a strong preference for polar molecules (Salter et al., 2002). This notion is further supported by the positive correlation that we observed between the charge of the proteins used in the current study and the fluorescent signal observed after treatment of microspore cells with CPP-mCherry proteins $(R=0.7)$. Additionally, the binding of R9-Cys-mCherry protein was relatively fast, dose-, and temperature-dependent (Figures 3, 4) that suggests for the solely physical-chemical interaction with the exine of the microspores. This however, possessed a challenge for the protein molecules internalization, since they were predominantly trapped on the outer layer of the cells (Figure 6). We hypothesized that a reversible covalent bond between $\mathrm{R} 9$ and mCherry protein would allow us to bring the cargo molecule to the close proximity of the micropore and through the plasma membrane, but the link will be reduced as soon as it enters the cell to accommodate the protein release inside the cytoplasm. Due to cytotoxicity of examined R9 CPP [Cys (Npys)-(D-Arg) 9 ] for microspore cells in the amount higher than 1 nmol (Figure 6), the complexes with CysmCherry were made at the molar ratios of $1: 1$. Consistent with our hypothesis, incubation with the (D-Arg) ${ }_{9}$-Cys-CysmCherry protein conjugates resulted in the cellular uptake of the fluorescent protein by live microspores (Figure 5). The protein was predominantly localized to cytoplasm and nucleus and was excluded from the vacuoles. At the same time we observed that some cells exhibited marked fluorescence as compared to others. This observation is in agreement with the previous report (Chang et al., 2005) and is apparently due to slightly different physiological stage of development of the cells in population. On the other hand, in contrast to other reports on non-covalent R9-mediated protein delivery into roots, we did not observe a detectable mCherry signal inside viable microspore cells when Cys-mCherry was complexed with $\mathrm{L}-\mathrm{R}_{9}$ at 1:1 molar ratio (Chang et al., 2007). This was probably due to the fact that we used almost 


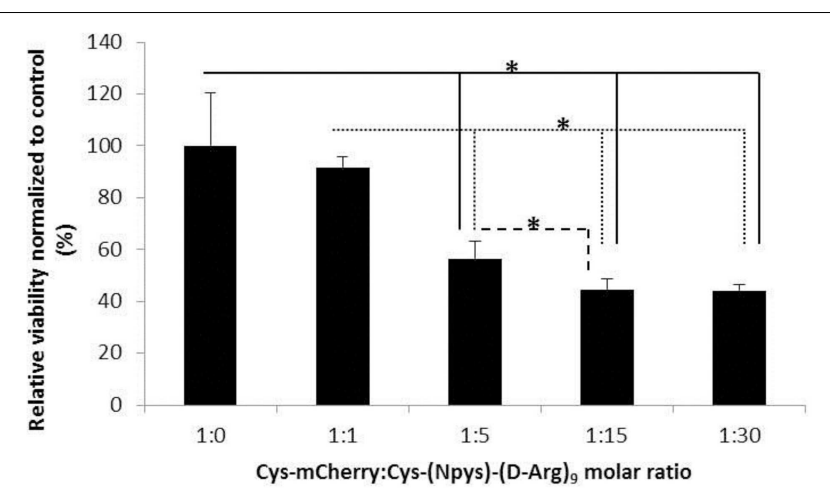

FIGURE 6 | Evaluation of Cys (Npys)-(D-Arg) 9 cytotoxicity on the microspore cells. The Cys-mCherry-CPP complex formation was done for $1 \mathrm{~h}$ in $100 \mu \mathrm{l}$ volume by combining $1 \mathrm{nmol}$ of the protein with the different amounts of Cys (Npys)-(D-Arg)g in indicated molar ratios. Later, 50,000 cells in $100 \mu \mathrm{l}$ volume were added to the reaction and the solution was incubated for $1 \mathrm{~h}$ at room temperature. Following the washing steps, the viability of microspores was quantified using FDA assay and the microplate reader. The data normalization was done by setting the fluorescent reading from the sample treated with the Cys-mCherry alone to $100 \%$. Data are shown as average calculated from three independent repeats with SD. The stars indicate statistically significant difference between connected bars (Student's $t$-test, single factor ANOVA, $\alpha=0.05, R^{2}=0.64$ ).

30 times lower final concentration of L-R9 in our transfection experiments as compared to the published study. The sensitivity of microspores to R9 CPP did not allow us to test higher amounts of this cationic peptide.

\section{References}

Asif, M., Eudes, F., Goyal, A., Amundsen, E., Randhawa, H., and Spaner, D. (2013). Organelle antioxidants improve microspore embryogenesis in wheat and triticale. In Vitro Cell. Dev. Biol. Plant 49, 489-497. doi: 10.1007/s11627013-9514-z

Barclay, I. R. (1975). High frequencies of haploid production in wheat (Triticum aestivum) by chromosome elimination. Nature 256, 410-411. doi: 10.1038/256410a0

Brew-Appiah, R. A., Ankrah, N., Liu, W., Konzak, C. F., von Wettstein, D., and Rustgi, S. (2013). Generation of doubled haploid transgenic wheat lines by microspore transformation. PLoS ONE 8:e80155. doi: 10.1371/journal.pone.0080155

Brisibe, E. A., Gajdosova, A., Olesen, A., and Andersen, S. B. (2000). Cytodifferentiation and transformation of embryogenic callus lines derived from anther culture of wheat. J. Exp. Bot. 51, 187-196. doi: 10.1093/jexbot/51.343.187

Chang, M., Chou, J. C., and Lee, H. J. (2005). Cellular internalization of fluorescent proteins via arginine-rich intracellular delivery peptide in plant cells. Plant Cell Physiol. 46, 482-488. doi: 10.1093/pcp/pci046

Chang, M., Chou, J. C., Chen, C. P., Liu, B. R., and Lee, H. J. (2007). Noncovalent protein transduction in plant cells by macropinocytosis. New Phytol. 174, 46-56. doi: 10.1111/j.1469-8137.2007.01977.x

Chang, M., Huang, Y. W., Aronstam, R. S., and Lee, H. J. (2014). Cellular delivery of noncovalently-associated macromolecules by cellpenetrating peptides. Curr. Pharm. Biotechnol. 15, 267-275. doi: $10.2174 / 1389201015666140617095415$

Chauhan, H., and Khurana, P. (2011). Use of doubled haploid technology for development of stable drought tolerant bread wheat (Triticum aestivum
Overall, in this communication we have described an approach that can be applied by other labs for examination of CPPs with different properties for their ability to interact with the totipotent cells like microspores. At the same time, we provide evidence that careful investigation of the internalization properties of any CPP-cargo is needed, due to physiological specificity of the specialized plant cells. The utilization of the reversible covalent bonds to convey cargos into the plant cells with the high negative charge of the outer layer is a preferable approach. Additionally, the same methodology can be further exploited for other cationic CPPs which may demonstrate higher internalization activity at the lower cytotoxicity rate. The implication of CPP technology for nano-cargo delivery into plant cells is still in its infancy, but, we believe, it holds a great potential for applied and basic studies due to its simplicity, high efficiency and an ability to deliver a wide spectrum of bioactive molecules into plant cells.

\section{Acknowledgments}

We thank Igor Kovalchuk for proofreading the manuscript. We acknowledge financial support from DOW AgroSciences LLC and A-Base funding from AAFC. We thank Grant Duke for technical assistance with confocal microscope.

\section{Supplementary Material}

The Supplementary Material for this article can be found online at: http://journal.frontiersin.org/article/10.3389/fpls.2015. 00666

L.) transgenics. Plant Biotechnol. J. 9, 408-417. doi: 10.1111/j.14677652.2010.00561.x

Chugh, A., Amundsen, E., and Eudes, F. (2009). Translocation of cell-penetrating peptides and delivery of their cargoes in triticale microspores. Plant Cell Rep. 28, 801-810. doi: 10.1007/s00299-009-0692-4

Derossi, D., Joliot, A. H., Chassaing, G., and Prochiantz, A. (1994). The third helix of the Antennapedia homeodomain translocates through biological membranes. J. Biol. Chem. 269, 10444-10450.

Folling, L., and Olesen, A. (2001). Transformation of wheat (Triticum aestivum L.) microspore-derived callus and microspores by particle bombardment. Plant Cell Rep. 20, 629-636. doi: 10.1007/s002990100371

Fonseca, S. B., Pereira, M. P., and Kelley, S. O. (2009). Recent advances in the use of cell-penetrating peptides for medical and biological applications. Adv. Drug Deliv. Rev. 61, 953-964. doi: 10.1016/j.addr.2009.06.001

Frankel, A. D., and Pabo, C. O. (1988). Cellular uptake of the tat protein from human immunodeficiency virus. Cell 55, 1189-1193. doi: 10.1016/00928674(88)90263-2

Futaki, S. (2002). Arginine-rich peptides: potential for intracellular delivery of macromolecules and the mystery of the translocation mechanisms. Int. J. Pharm. 245, 1-7. doi: 10.1016/S0378-5173(02)00337-X

Gaj, T., Guo, J., Kato, Y., Sirk, S. J., and Barbas, C. F. III. (2012). Targeted gene knockout by direct delivery of zinc-finger nuclease proteins. Nat. Methods 9 , 805-807. doi: 10.1038/nmeth.2030

Green, M., and Loewenstein, P. M. (1988). Autonomous functional domains of chemically synthesized human immunodeficiency virus tat trans-activator protein. Cell 55, 1179-1188. doi: 10.1016/0092-8674(88)90262-0

Hallbrink, M., Floren, A., Elmquist, A., Pooga, M., Bartfai, T., and Langel, U. (2001). Cargo delivery kinetics of cell-penetrating peptides. Biochim. Biophys. Acta 1515, 101-109. doi: 10.1016/S0005-2736(01)00398-4 
Hu, T., and Kasha, K. J. (1999). A cytological study of pretreatments used to improve isolated microspore cultures of wheat (Triticum aestivum L.) cv. Chris. Genome 42, 432-441. doi: 10.1139/ gen-42-3-432

Huang, Y., Jiang, Y., Wang, H., Wang, J., Shin, M. C., Byun, Y., et al. (2013). Curb challenges of the "Trojan Horse" approach: Smart strategies in achieving effective yet safe cell-penetrating peptide-based drug delivery. Adv. Drug Deliv. Rev. 65, 1299-1315. doi: 10.1016/j.addr.2012.11.007

Hul, T., and Kasha, K. J. (1997). Improvement of isolated microspore culture of wheat (Triticum aestivum L.) through ovary co-culture. Plant Cell Rep. 16, 520-525. doi: 10.1007/BF01142316

Kumlehn, J., Serazetdinova, L., Hensel, G., Becker, D., and Loerz, H. (2006). Genetic transformation of barley (Hordeum vulgare L.) via infection of androgenetic pollen cultures with Agrobacterium tumefaciens. Plant Biotechnol. J. 4, 251-261. doi: 10.1111/j.1467-7652.2005.00178.x

Laurie, D. A., and Bennett, M. D. (1988a). The production of haploid wheat plants from wheat $\times$ maize crosses. Theor. Appl. Genet. 76, 393-397. doi: 10.1007/BF00265339

Laurie, D. A., and Bennett, M. D. (1988b). Cytological evidence for fertilization in hexaploid wheat $\times$ sorghum crosses. Plant Breed. 100, 73-82. doi: 10.1111/j.1439-0523.1988.tb00220.x

Lindgren, M., and Langel, U. (2011). Classes and prediction of cell-penetrating peptides. Methods Mol. Biol. 683, 3-19. doi: 10.1007/978-1-60761-919-2_1

Liu, B. R., Liou, J. S., Huang, Y. W., Aronstam, R. S., and Lee, H. J. (2013). Intracellular delivery of nanoparticles and DNAs by IR9 cell-penetrating peptides. PLoS ONE 8:e64205. doi: 10.1371/journal.pone. 0064205

Liu, J., Gaj, T., Patterson, J. T., Sirk, S. J., and Barbas, C. F. III. (2014). Cell-penetrating peptide-mediated delivery of TALEN proteins via bioconjugation for genome engineering. PLOS ONE 9:e85755. doi: 10.1371/journal.pone.0085755

Liu, J., Gaj, T., Wallen, M. C., and Barbas, C. F. III. (2015). Improved cellpenetrating zinc-finger nuclease proteins for precision genome engineering. Mol. Ther. Nucleic Acids 4, e232. doi: 10.1038/mtna.2015.6

Oehlke, J., Scheller, A., Wiesner, B., Krause, E., Beyermann, M., Klauschenz, E., et al. (1998). Cellular uptake of an alpha-helical amphipathic model peptide with the potential to deliver polar compounds into the cell interior nonendocytically. Biochim. Biophys. Acta 1414, 127-139. doi: 10.1016/S00052736(98)00161-8

Pooga, M., Hällbrink, M., Zorko, M., and Langel, U. (1998). Cell penetration by transportan. FASEB J. 12, 67-77.

Quilichini, T. D., Friedmann, M. C., Samuels, A. L., and Douglas, C. J. (2010). ATP-binding cassette transporter G26 is required for male fertility and pollen exine formation in arabidopsis. Plant Physiol. 154, 678-690. doi: 10.1104/pp.110.161968

Ramakrishna, S., Kwaku Dad, A. B., Beloor, J., Gopalappa, R., Lee, S. K., and Kim, H. (2014). Gene disruption by cell-penetrating peptide-mediated delivery of Cas9 protein and guide RNA. Genome Res. 24, 1020-1027. doi: $10.1101 /$ gr.171264.113
Resch, T., and Touraev, A. (2010). "Pollen transformation technologies," in Plant Transformation Technologies, eds C. N. Stewart, A. Touraev, V. Citovsky, and T. Tzfira (Oxford, UK: Wiley-Blackwell), 83-91. doi: 10.1002/978047095 8988.ch5

Salter, J., Murray, B. G., and Braggins, J. E. (2002). Wettable and unsinkable: the hydrodynamics of saccate pollen grains in relation to the pollination mechanism in the two New Zealand species of Prumnopitys Phil. (Podocarpaceae). Ann. Bot. 89, 133-144. doi: 10.1093/aob/mcf019

Scheller, A., Oehlke, J., Wiesner, B., Dathe, M., Krause, E., Beyermann, M., et al. (1999). Structural requirements for cellular uptake of $\alpha$-helical amphipathic peptides. J. Pept. Sci. 5, 185-194.

Sinha, R., and Eudes, F. (2015). Dimethyl tyrosine conjugated peptide prevents oxidative damage and death of triticale and wheat microspores. Plant Cell Tissue Organ Cult. 122, 227-237. doi: 10.1007/s11240-015-0763-x

Tang, X., Liu, Y., He, Y., Ma, L., and Sun, M.-x. (2013). Exine dehiscing induces rape microspore polarity, which results in different daughter cell fate and fixes the apical-basal axis of the embryo. J. Exp. Bot. 64, 215-228. doi: $10.1093 /$ jxb/ers327

Touraev, A., Indrianto, A., Wratschko, I., Vicente, O., and Heberle-Bors, E. (1996). Efficient microspore embryogenesis in wheat (Triticum aestivum L.) induced by starvation at high temperature. Sex. Plant Reprod. 9, 209-215. doi: 10.1007/BF02173100

Vivès, E., Brodin, P., and Lebleu, B. (1997). A Truncated HIV-1 tat protein basic domain rapidly translocates through the plasma membrane and accumulates in the cell nucleus. J. Biol. Chem. 272, 16010-16017. doi: 10.1074/jbc.272.25.16010

Voytas, D. F., and Gao, C. (2014). Precision genome engineering and agriculture: opportunities and regulatory challenges. PLoS Biol. 12:e1001877. doi: 10.1371/journal.pbio.1001877

Wang, F., Wang, Y., Zhang, X., Zhang, W., Guo, S., and Jin, F. (2014b). Recent progress of cell-penetrating peptides as new carriers for intracellular cargo delivery. J. Control. Release 174, 126-136. doi: 10.1016/j.jconrel.2013.11.020

Wang, Y., Cheng, X., Shan, Q., Zhang, Y., Liu, J., Gao, C., et al. (2014a). Simultaneous editing of three homoeoalleles in hexaploid bread wheat confers heritable resistance to powdery mildew. Nat. Biotechnol. 32, 947-951. doi: $10.1038 /$ nbt.2969

Zadoks, J. C., Chang, T. T., and Konzak, C. F. (1974). A decimal code for the growth stages of cereals. Weed Res. 14, 415-421. doi: 10.1111/j.13653180.1974.tb01084.x

Conflict of Interest Statement: The authors declare that the research was conducted in the absence of any commercial or financial relationships that could be construed as a potential conflict of interest.

Copyright (C) 2015 Her Majesty the Queen in Right of Canada. This is an open-access article distributed under the terms of the Creative Commons Attribution License (CC $B Y)$. The use, distribution or reproduction in other forums is permitted, provided the original author(s) or licensor are credited and that the original publication in this journal is cited, in accordance with accepted academic practice. No use, distribution or reproduction is permitted which does not comply with these terms. 